Results Evidence supports PSC as a 'cause of the causes' of work stress, and a theoretical precursor to many job designbased work stress theories.

Discussion This presentation will discuss contemporary economic policies, work stress issues, PSC theory and evidencebased implications for organisations and national level, policy, practices and procedures for worker psychological health. The presentation will highlight how PSC affects working conditions, employee health and well-being, and organisational outcomes, with evidence from around the globe.

\section{FROM FRAGMENTATION TO A HOLISTIC VIEW OF THE WORKING LIFE: CHALLENGES, POSSIBILITIES AND SOLUTIONS}

Pauli Forma. Keva, Helsinki, Finland

\subsection{6/oemed-2018-ICOHabstracts. 17}

The working life is changing significantly especially due to technological development. Among the most important technological drivers are digitalization, development of artificial intelligence and increasing role of the platform economy. These trends have substantial impact on the different areas of the working life. Entire industries will be under disruption, skills and competencies needed in different occupations are going to change and totally new occupations and job functions will be created. The development also has many consequences to the occupational safety and health. Improving occupational safety and health has always been based on data and cumulated knowledge. However, technological development and changing working life is going to change the utilisation of the data. Challenges as well as possibilities can be identified here. When it comes to challenges, first, the relevant data is fragmented. At the national level, different institutions, organisations and authorities have data concerning some part of the working life. Different data-sets can include information on work disability, work accidents, occupational health or wellbeing at work. Due to this fragmentation, the picture concerning the working life is incomplete. The second challenge is that the traditional data and classifications may be inadequate. For example, new categories of employment (e.g. platform workers) are created and traditional datasets do not provide information on their risks, work ability and wellbeing. We might even need a totally new segmentation model for the occupational safety and health. Third, we lack data concerning the new risks on occupational safety and health due to digitalization and other aspects of the changing working life.

However, possibilities can also be identified. Because of the digitalization, data is produced in almost every action we take before, during and after the working day. This data can be related for example to working hours, productivity, wellbeing, health, stress and recovery. In a way, the entire 'digital working day' can be measured and this information can be used to improve occupational safety and health. Sources for this type of data can be HR-systems, registers, platforms and employees' own devices (My Data). Thus, in addition to traditional data-sources we have to use also new sources of data on occupational safety and health. It is also evident that due to digitalization we have more tools to analyse the data. When it comes to solutions, the Finnish project 'National Working Life Indicators', which tries to overcome these challenges and benefit these possibilities, will be demonstrated. The aim of the project is to provide near online information concerning the Finnish working life and occupational safety and health. In the project, relevant data focusing on different aspects of the working life will be collected to one data-base. Both traditional data-sources and big data will be used. Based on the data, key-indicators describing development of the Finnish working life will be identified. The data-base will include traditional data (e.g. survey-data and registers) as well as 'big data.' The portal makes it possible for the different stakeholders to access the data through the dashboard. The aim of the database is to support decision-making, research and improving occupational safety and health.

\section{THE ROLE OF EDUCATION AND TRAINING TO SUSTAIN AND DEVELOP AN OCCUPATIONAL HEALTH WORKFORCE FOR THE BENEFIT OF WORKING PEOPLE}

${ }^{1,2}$ John Harrison. 'National School of Occupational Health, Health Education England, London, UK; ${ }^{2}$ Business School, Brunel University, Uxbridge, London, UK

\subsection{6/oemed-2018-ICOHabstracts. 18}

Introduction The world of work in the twenty-first century presents a number of challenges to occupational health practitioners. Why should organisations invest in occupational health provision? What are the political, economic and social drivers and how will changes in technology and the environment influence the competencies and composition of future occupational health workforces? Education and training must prepare practitioners for practice that is relevant and marketable to improve the reach and efficacy of occupational health, as well as underpinning attractive careers. This talk will review work that is on-going to address these issues.

Methods Consideration of different initiatives globally, with particular reference to work in the United Kingdom regarding the development of a multidisciplinary occupational health workforce.

Discussion Education and training must address structural differences in occupational health provision, as described in the basic occupational health services model. Future occupational health workforces will be multidisciplinary and viewed holistically as part of a public health provision. Wellbeing at work is contingent on assessing and meeting a hierarchy of workplace and organisational needs and practitioners will need the requisite competencies to meet market demands. Consideration is necessary as to how established training provision will adapt to deliver accessible, timely, affordable and effective educational resources.

\section{NATIONAL SURVEY OF WELLBEING OF HOSPITAL DOCTORS IN IRELAND}

1,2Blanaid Hayes. 'Dean, Faculty of Occupational Medicine, Royal College of Physicians in Ireland, Dublin, Ireland; ' ${ }^{2}$ Consultant Occupational Physician, Beaumont Hospital, PO Box 1297, Dublin, Ireland

\subsection{6/oemed-2018-ICOHabstracts. 19}

Introduction Doctors' wellbeing is increasingly attracting the attention of researchers. It is of interest of itself and because of its potential impact on the health of others. In the wake of the global recession of the past decade, Ireland dramatically cut its healthcare expenditure resulting in significant staff 
shortages at a time of growing population, more challenging healthcare delivery and increased societal expectation. This has created a highly challenging psychosocial environment for healthcare workers. Consultants feel undervalued and are concerned about the quality of care they provide. They perceive care to be thwarted by managers being reactive and not focused on longterm planning. As well as feeling undervalued, trainees too have concerns about the quality of care they provide and they struggle to manage both service and training demands.

Method Utilising validated questionnaires, a national cross-sectional survey of hospital doctors, undertaken in 2014, sought responses from consultants and trainees working in the sector. The response rate was 55\%.

Results Hospital doctors in Ireland had higher levels of psychological distress than elsewhere. They also had significant symptoms of depression and anxiety as well as high levels of burnout and occupational stress. Self-stigma in relation to mental illness was more common in doctors than in the general population. However, current desire to practice remained high.

Discussion The high levels of personal and workplace distress identified in this study suggest that much needs to be done to highlight the importance of doctors' wellbeing in this country. Self-stigmatisation is likely a barrier to early identification and treatment of mental health problems. Post-graduate training bodies have already begun to address these issues with trainee and trainer members. Occupational health services have a key role to play in ensuring appropriate access to care and in determining necessary workplace restrictions and/or supports for this group.

\section{OCCUPATIONAL HEALTH AND EPIDEMIOLOGICAL METHODS RESEARCH: CHALLENGES AND OPPORTUNITIES}

Jain Rajiv Kumar. Vice President, Association of Environmental and Occupational HealthDelhi

\subsection{6/oemed-2018-ICOHabstracts.20}

Purpose It is widely accepted that there is definite need for strengthening research in developing, validating and refining epidemiological methods for application in Occupational Health, if preventive strategies have to be devised on actual evidence. There is need to further identify and manage the challenges and also diffuse the opportunities available for collaboration in conducting research in Epidemiological Methods for Occupational Health.

Review and discussion Developing improved methods for exposure assessment, statistical analysis, studying migrant workers and other vulnerable populations, the use of biomarkers, and new hazards provide challenges and opportunities.

Issues of challenges due to lack of validated statistical tools, complexity of ethical considerations, lack of training in occupational epidemiological methods, non-clarity in methods for accurate determination of proportion of disease/diseases attributable to occupation, shifting of hazardous industries from developed to developing countries, lack of collaboration mechanisms with veterinary epidemiologists, lack of participatory research, effective and appropriate communicating tools, preventability paradox and maintaining public health perspective to ensure proper population perspective, shall be discussed.
Conclusion and outcome Opportunities for developing, nurturing, financing and implementing local, regional and global collaboration through fair, transparent, democratic and participative consortiums/forums/alliances of people, civil society and public and private institutions and Governments, in the field of epidemiological methods research shall be explored and discussed. A case for germinating an Institute of Occupational Health Metrics and Evaluation in a developing country environment shall be built upon.

\section{DEVELOPMENT OF OCCUPATIONAL HEALTH NURSING ASSESSMENT TOOLS FOR INDIVIDUAL AND GROUP/ ORGANISATION}

Keiko Kono. Research Centre for Occupational Health Nursing, Yokkaichi Nursing and Medical Care University/Japan

\subsection{6/oemed-2018-ICOHabstracts.21}

Introduction In order to provide high quality activities in occupational health $(\mathrm{OH})$ nursing, it is essential to assess the worker and the group/organisation. However, these kind of tools have not been available until we developed the $\mathrm{OH}$ nursing assessment tools. Methods we have developed the assessment tools for both individual and group/organisation by the task force consisting of $17 \mathrm{OH}$ nurses from 2000 through 2014. In the development of the tool for Individual, we based on the frame work of North American Nursing Diagnosis International (NANDA I), and for group/organisation we referred to the Community as Partner Model by Anderson and the Hanasaari Conceptual Model which was developed in the 1 st International Symposium on $\mathrm{OH}$ Nursing Education in Finland in 1988.

Results The tool for Individual has been divided into 13 domains with a face sheet. By using the face sheet, we can capture work/life style history of individual effectively. The 13 domains consist of Health Promotion, Nutrition, Elimination, Activity/Rest, Perception/Cognition, Self-Perception, Role Relationships, Sexuality, Coping/Stress Tolerance, Life Principle, Safety/Protection, Comfort and Growth/Development. The tool for group/organisation has been comprised 8 core items (Company Outline, Organisation Outline, Constitution of the Worker, Human Resources/Labour Management/Education, Culture, Labour Condition, Health Status and Safety/Health), which directly related with the worker belonging to the group/organisation, and 5 sub-items (Administration, Economy, Environment, Social Resource and Traffic), which will be indirectly related with the worker.

Conclusion These tools are useful to catch the information about workers and their surroundings including labour standpoint. As the result, currently many $\mathrm{OH}$ nurses in Japan utilise these tools in daily work that can help them to assess the worker holistically and to assess the group/organisation comprehensively and systematically.

\section{KNEE ARTHROPLASTY AND THE UNFORESEEN IMPACT ON WORK}

Paul FM Kuijer. Academic Medical Centre, University of Amsterdam, Coronel Institute of Occupational Health, People and Work Outpatient Clinic, Amsterdam Public Health research institute, Amsterdam, the Netherlands

10.1136/oemed-2018-ICOHabstracts.22 